\title{
Xenobiotics: a Threat to the Health of Living Organisms
}

\author{
Svetlana V. Kucherenko*, Alla M. Ovcharenko, and Sergey L. Pushenko \\ Don State Technical University, Gagagrina Square, 1, Rostov-on-Don, Russia
}

\begin{abstract}
The article summarizes and analyzes the main impacts of various xenobiotics or their groups on the human body and the consequences of such exposure. The study suggests the refinements to the generally accepted classification of xenobiotics' origins. The paper also describes the molecular mechanism of foreign substances biotransformation in a human body. The metabolism of xenobiotics differs due to their forms and types' varieties. The factors of influence on chemicals' metabolism are also of great importance. Individual features of the metabolism may be associated with genetic differences in the activity of metabolic enzymes. The research results further the comprehension of the exposure pathways and health impacts of the xenobiotics and their metabolites.
\end{abstract}

\section{Introduction}

In the last decades, the environmental contamination by xenobiotics, and, therefore, its intake by living organisms, rapidly increases [1, 2]. The introduction of these substances to the ecosystems could cause an increase in allergic reactions, organisms' mortality, genetic alterations, lowering of immune systems, metabolic disorders, and disruptions in the processes in the natural ecosystems up to the biosphere level [3]. The xenobiotic-induced cell damage and mutations lead to malignancy or hereditary diseases. Therefore, these substances are significant risks to the well-being and health of living organisms $[4,5]$. Children become the "target" of xenobiotics exposure. It is manifesting with increased fatigue, physical inactivity, functional (i.e., not detected by laboratory and instrumental methods) disorders of the central nervous system, gastrointestinal, biliary, and urinary tracts, along with a decline in interest in the outside world, recurrent SARS, bronchitis, pneumonia, and multiple allergies.

The world produces up to 1 million items per year of new products, including approximately 100 thousand chemical compounds. The potential xenobiotics consist of nearly 15 thousand of this amount. The foodstuff contamination with pesticides, hormones, and trans-fatty acids is particularly hazardous. According to the researches conducted in the USA, there were DDE remains in 100 percent of raisins, spinach, and beef, 93 percent of cheeses, sausages, chicken, turkey, and ice-cream, 87 percent of salami and oil, 81 percent of cheddar and half-smoked sausages. Out of more than 2 million tons of pesticides used

\footnotetext{
* Corresponding author: kuh-sv82@mail.ru
} 
annually worldwide, only 0.1 percent reach the pests; the remaining $99.9 \%$ enter the water. Chlorinated pesticides DDE and DDT persist in soil for decades [6].

Xenobiotics have a presence in food as colorants, thickeners, emulsifiers, stabilizers, flavorings, preservatives, etc., and become more and more dangerous year after year. Fumes from copy paper, printers, office dust, air conditioners are the hazards introduced to human health during office work. Sick building syndrome manifests in chest heaviness, shallow breathing, flu-like condition, nasal congestion, etc. With the added influences of toxic emitted gases of motor vehicles and electromagnetic radiation, which are the constant surrounding factors, the need to protect the human organism against the negative environmental impacts is apparent.

Pesticides, often used in agriculture and various industries as plant protection agents, have been found in a vast range of products. The research [7] determines these substances' potential health risk distinguishing their routes of human exposure: by direct contact, by water consumption, or food chain.

This study aims to analyze the properties of xenobiotics' varieties and their health effects.

\section{Materials and methods}

With the classical approach, all xenobiotic compounds divide by origin between the natural and technological (synthetically produced). Natural xenobiotics are splitting into three blocks: biological substances synthesized by bacteria, mushrooms, plants and animals, inorganic compounds, and organic substances of non-biological origins. By application, the natural xenobiotics divide into ingredients and by-products of chemosynthesis and special industry branches, pesticides, pharmaceuticals and cosmetics, food additives, fuels and oils, solvents, coloring agents, glues, contaminants, and refuses. Natural xenobiotics are part of vegetables, mushrooms, fruits. With a general diet, the daily intake of xenobiotics of natural origin is $2 \mathrm{~g}$, while the pesticide consumption is $0.09 \mathrm{mg}[4,6]$. Many natural xenobiotics have carcinogenic activity. Nevertheless, some of the food nutrients (in particular, ascorbic acid, vitamins $\mathrm{A}$ and $\mathrm{E}$, the plant monoterpene limonene) possess anticarcinogenic properties that neutralize carcinogenic impact.

The primary sources of technological xenobiotics are industrial sectors, such as oil and gas processing, thermal and nuclear energetics, air and ground transportation complex, etc. $[1,5,8]$. There are many high toxic xenobiotics of synthetic origins circulating in the biosphere. While the term "technological xenobiotics" is not generally recognized, and its use is to some extent arbitrary, it still allows one to single out from a large number of pollutants those that pose the greatest danger to humans. This large group of hazardous substances includes agents that, with a local effect of relatively high concentrations associated with accidents or military actions, can cause acute poisoning and mortality (dioxins, polychlorinated biphenyls, some organophosphorus compounds). Like the organic xenobiotics', the technological ones' micro amounts scattered presence in the environment causes a whole spectrum of eco-pathologies under chronic exposure. In addition to these super toxins, this group includes pesticides, polycyclic aromatic hydrocarbons (PAHs), chlorinated phenols, aromatic amines, some plastic monomers, polymeric materials, and other synthetic organic substances. Most technogenic xenobiotics are stable and highly cumulative agents. Having similarities with the organic components of living organisms, they freely move through trophic chains with significant accumulation rates. Since many of that substances are hydrophobic, i.e., poorly soluble in water, their predominant accumulation occurs in adipose tissue and cell phospholipids. Technogenic xenobiotics attach active radicals. Some of them are capable of invading the DNA structure. It is the reason for their carcinogenic, mutagenic, and embryotoxic effects. 
But regardless of the xenobiotic's source, its adverse impact always manifests itself in a general toxic, irritating, and sensitizing effect.

The late manifestation of exposure effects stems from xenobiotics' gonadotropic (benzene, chloroprene, caprolactam, lead, etc.), neurotropic, mutagenic, and carcinogenic factors. The primary distinguishing characteristic of xenobiotics is the longevity of their health impacts with the minimal amounts of effective concentrations.

This study proposes to take a closer look at the xenobiotics' metabolism in the human body implemented by the micro-biome populating the gastrointestinal tract. The medicinal products, toxic substances, and heavy metals pharmacokinetics lead to abnormal metabolism of the human body [9]. Micro-organisms populating the gastrointestinal tract are participating in the fission of xenobiotics. The unique enzymes coded in the microbiome can limit the small intestine's absorption of xenobiotics. It happens due to the increase in the adhesive micelle proteins supporting the protective layer of mucosa. While the microbiome affects the host and the xenobiotic's pharmacokinetics, there is a substance's impact on the viability and metabolism of the micro-organisms. The design and advancement of simulation systems and mechanistic researches focused on the human and micro-biome contributions in xenobiotics disintegration will promote the comprehension of the complex relationships between host, microbiome, and metabolism.

The glucocorticoid receptor (GR) is present in almost every type of human cells [10]. GR represents several different isoforms that act as ligand-dependent transcription factors that regulate glucocorticoid-sensitive genes in both positive and negative ways. Xenobiotics, ubiquitous in the environment, bind to GR and are also able to activate or suppress it. By modulating GR cells and tissues, they enable responses to the inflammatory, allergic, metabolic, tumor, and autoimmune processes. The GR and xenobiotics' cooperation is becoming increasingly relevant while researching the population aging and associated prevalence of tumor diseases, as well as the growing concern about human exposure to chemical pollutants.

Cells adapt to foreign substances impacts activating the biosynthesis of proteins involved in xenobiotic metabolism [11]. The process is achieved mainly by activating cellular xeno-sensors that modulate the effect on genes. Biotransformation of xenobiotics often occurs with the formation of reactive oxygen species. In turn, known process modulators encode antioxidant proteins creating a regulatory chain and a cells' adaptive response to xenobiotics.

Currently, interest in xenobiotics is restoring due to the recent re-evaluation of dietary antioxidants, namely polyphenols, as moderately harmful compounds rather than authentic antioxidants in vivo [12]. Consequently, the role of xenobiotics in human health is changing. Although many food compounds are toxic when consumed in excessive amounts, a wide range of plant-derived xenobiotics, namely polyphenols, actually activate phase II enzymes and strengthen our defenses against subsequent harmful stimuli. The exposure pathway may be of paramount importance for restoring proper detoxification capacity, for example, in older people or during oxidative stress and increased exposure to pollutants. Therefore, due to genetic and age differences, the fine-tuning of phase II enzymes' consumption may be necessary. Well-known examples include lipoic acid and a plant, such as olive polyphenols, which in sufficient quantities can play an important protective role, in addition to their common antioxidant effects. Nevertheless, this intriguing hypothesis has not been confirmed in humans and requires appropriate research.

Mitochondria play a crucial role in energy metabolism, signaling pathways, and overall cell viability [13]. They are at the forefront of meeting the energy needs of cells under stress, for example, in response to xenobiotic exposure. The recent research highlights a new regulatory key role of miRNAs in crucial signaling pathways in mitochondria [6]. The xenobiotic-induced changes in miRNAs expression can lead to mitochondrial dysfunction, 
overexpression of reactive oxygen species, and release of apoptosis or necrosis of activating proteins.

The basis of an ideal experimental model for in vitro toxicological analysis is the freshly isolated cells [14]. In particular, this method is applicable for detecting a variety of xenobiotic-induced genotoxic effects. The in vitro model uses typical xenobiotics such as heavy metals ( $\mathrm{Zn}, \mathrm{Cu}, \mathrm{Cd}, \mathrm{Pb}$ ) and polychlorinated biphenyls (PCBs) to estimate the genotoxic effects in sea mussel (Mytilus galloprovincialis) cells. DNA damage and chromosomal aberrations were evaluated in freshly isolated hemolymph, gill, and digestive gland cells by gel electrophoresis and micronucleus analysis, respectively. The Cu-induced DNA aberrations in hemocytes were significantly higher than $\mathrm{Cd}$ - and Pb-induced ones, thus, indicating chemically specific genotoxicity. The combined exposure to PCBs and heavy metals results in an additive effect, suggesting the interaction of the said xenobiotics. The genetic responses are proven to arise and maintain in vitro against short-term stresses caused by foreign substances. The in vitro model application can provide a quick tool for investigating complex toxic effects in marine invertebrates and monitoring the environment.

\section{Results and discussion}

Besides the widely acknowledged classification of xenobiotics' origins, the represented study highlights the other ways of its genesis. First of all, it is the fermentation of food components and products with expired terms and failed storage standards. Secondly, the genetic changes in fruit and vegetable seeds also generate xenobiotics. This genetic modulation prevents the body's enzyme systems from assimilating these foods normally [15]. A human body does not have high-speed adaptation mechanisms for change in absorption systems or the emergence of new ones; our organism is an inertial system. Another variant of xenobiotic manifestation is incomplete oxidation or restoration of food molecules in the body with incomplete assimilation of organic substances. In this case, the energetic parity occurs (table 1). Under normal conditions, there is a balanced oxidized $(\mathrm{NAD}+)$ to reduced $(\mathrm{NADH})$ nucleotides ratio in the human organism. The NAD+ predominance implies the presence of xenobiotic elements of food molecules, including peroxide molecules [16, 17].

The matter of barrier systems state in the human body currently intensifies due to changes in the natural environment, its oversaturation of foreign substances. The liver is the main xenobiotic protector of an organism because it is the first organ "meeting" the said substance in the human body.

Biotransformation (metabolism) of xenobiotics includes two phases:

1) metabolic reactions - their transformation into more polar metabolites (oxidation, reduction, hydrolysis);

2) conjugation reactions (combination with proteins, amino acids, glucuronic and sulfuric acids). 
Table 1. The revised classification of xenobiotics by origin.

\begin{tabular}{|c|c|c|}
\hline Feature & Formation mechanism & Typical representatives \\
\hline \multirow[t]{3}{*}{$\begin{array}{l}\text { Natural } \\
\text { origins }\end{array}$} & $\begin{array}{l}\text { Volcanoes and natural } \\
\text { emissions }\end{array}$ & $\begin{array}{l}\text { Carbon and sulfur mono- and dioxides, hydrogen sulfide, } \\
\text { fluorine and chlorine compounds }\end{array}$ \\
\hline & $\begin{array}{l}\text { Non-biological organic } \\
\text { compounds }\end{array}$ & Aliphatic and aromatic hydrocarbons \\
\hline & Biological compounds & Animals and plant poisons (aconite, hemlock) \\
\hline \multirow{6}{*}{$\begin{array}{l}\text { Technogenic } \\
\text { origins }\end{array}$} & Industrial & Chrome, nickel, manganese, formaldehyde \\
\hline & Agricultural & $\begin{array}{l}\text { Organochlorine pesticides, organophosphate insecticides, } \\
\text { bactericides, herbicides, zoocides, fungicides }\end{array}$ \\
\hline & Construction materials & $\begin{array}{l}\text { Aniline, freon, methyl alcohol, plasticizers, polymers } \\
\text { (polyvinyl chloride), styrene, formaldehyde, phenol, } \\
\text { epoxy resin }\end{array}$ \\
\hline & Household chemicals & $\begin{array}{l}\text { Alcohols, } \\
\text { dimethylphthalate, heavy metals, methylenechloride }\end{array}$ \\
\hline & Farmaceuticals & $\begin{array}{l}\text { Antibiotics, sulfonamides, mercury preparations, iodides, } \\
\text { arsenic preparations, barbiturates, dietary supplements }\end{array}$ \\
\hline & Transportation & $\begin{array}{l}\text { Methane, butane, propane, heavy metals, chloramine, } \\
\text { mono-and carbon dioxide, polycyclic aromatic } \\
\text { hydrocarbons (benzo(a)pyrene) }\end{array}$ \\
\hline \multirow{5}{*}{$\begin{array}{l}\text { Bio- } \\
\text { transformed } \\
\text { xenobiotics }\end{array}$} & Fermentation products & Alkaloids, cyclopeptides \\
\hline & $\begin{array}{l}\text { Genetically modified } \\
\text { seeds and field crops }\end{array}$ & $\begin{array}{l}\text { Products with genetically engineered ingredients, } \\
\text { products of processing of transgenic raw materials, } \\
\text { transgenic vegetables and fruits }\end{array}$ \\
\hline & Expired food products & Microscopic fungal metabolites and bacterial toxins \\
\hline & Food industry & $\begin{array}{l}\text { Antioxidants, preservatives, vitamins, minerals, flavors, } \\
\text { food colorants, emulsifiers, stabilizers, thickeners }\end{array}$ \\
\hline & $\begin{array}{l}\text { Toxic substances formed } \\
\text { in food as the } \\
\text { endogenous impurities }\end{array}$ & Toxins of non-pathogenic and pathogenic fungi \\
\hline
\end{tabular}

The aim of these reactions is the formation of non-toxic hydrophilic compounds, which are involved in other metabolic transformations, transported by the blood, and excreting from the body. The families of cytochromes P450 CYP1, conjugation enzymes and transport proteins participate in the biotransformation of xenobiotics. As a result, the xenobiotic(A) disintegrates with the breaking of covalent bonds:

$$
\begin{gathered}
\mathrm{A} \rightarrow \mathrm{A}-\mathrm{OH} \\
\mathrm{A}-\mathrm{OH}+\mathrm{O}_{2} \rightarrow \mathrm{A}-\mathrm{H}_{2} \mathrm{O},
\end{gathered}
$$

then, accordingly, becomes water-soluble and, finally, naturally removable from the body with the help of the kidneys. Energetically, the organism processes the xenobiotics utilizing ATP molecules.

In the human body, endogenous water provides the necessary oxygen for xenobiotics oxidation. Schematically, the representing process is as follows:

$$
\mathrm{O}_{2} *+\mathrm{H}^{+}+\mathrm{H}^{+}
$$

The most often case of water dissociation is as follows:

$$
\mathrm{H}_{2} \mathrm{O} \rightarrow \mathrm{OH}^{-}+\mathrm{H}^{+}
$$


The main danger is the oxygenation of iron cation from divalent to trivalent. This process generates a superoxide anion in the cell membranes. The various enzymatic systems operating in certain parts of the metabolic process form their own hydrogen peroxide. Being a highly toxic substance, it can affect a nearby xenobiotic at the time of its occurrence in the process of metabolism. Nevertheless, unlike enzymes, hydrogen peroxide is unmanageable in its manifestation.

$$
\mathrm{H}_{2} \mathrm{O}_{2} \rightarrow \mathrm{H}_{2} \mathrm{O}+\mathrm{O}^{-}
$$

The atomic oxygen $\left(\mathrm{O}^{-}\right)$produced by the reaction is dangerous for the cells' mitochondria DNA. As a result, the cells' energy losses, damage to the Golgi apparatus, a membranes' breakdown, cell aging, and shortening of DNA chains occur.

\section{Conclusions}

Despite the evolutionary formation of neutralization and removal systems for bodyinvading agents, the ongoing biotransformation process consistently attempts to balance the metabolic activation of xenobiotics to the detoxification of their mutagenic metabolites. A violation of this balance in the human body can lead to both increase and a decrease in DNA damage. For different people, the toxicity of xenobiotics varies quite widely. These fluctuations are due to the increased sensitivity of the organism and intraspecific variability. Currently, a wide range of chemicals is known to be absolutely foreign to the human organism. These substances have toxic and irritating effects on various human organs and systems, both direct and mediated through metabolites.

The problem of xenobiotics researching is getting complicated by the variety of forms and types of these foreign substances. Factors affecting the xenobiotics metabolism are also of great importance. Individual features of the metabolism may be associated with genetic differences in the activity of metabolic enzymes. The main physiological factor is age. The young children and the elderly metabolism is known to differ from the usual one. The majority of newborns have the enzymes responsible for oxidative metabolism and conjugation underdeveloped or in insufficient quantities. The metabolism of drugs is affected by the dose, purity, exposure route, distribution in the tissues, and the compound's ability to bind to proteins. Pharmaceuticals and other xenobiotics compete for the active centers of enzymes, which reduces the metabolism. Finally, toxic chemicals (pesticides, carbon monoxide) "poison" the enzymes and reduce the metabolism.

The represented results further the study of the impacts of xenobiotic decomposition products in the human body.

\section{References}

1. K. Kobzev et al, E3S Web of Conferences, 217, 11001 (2020)

2. K. Kobzev et al, E3S Web of Conferences, 217, 11013 (2020)

3. T. N. Kovaleva et al., Ekoloji, 28(107), 5039 (2019)

4. S. V. Kucherenko, Interagromash, 1, 178 (2020)

5. E. V. Omelchenko et al, Conf. Ser.: Earth Environ. Sci., 66, 012032 (2017)

6. Kip E. Panter, Bryan L. Stegelmeier, Veterinary Clinics of North America: Food Animal Practice, 27, 429 (2011)

7. V. Bespalov, E. Kotlyarova, IOP Conf. Ser. Earth Envir. Sci. 177, 012036 (2018)

8. Polyxeni Fountoucidoua et al, Toxicology Letters, 317, 24 (2019) 
9. Stephanie L. Collinsa, Andrew D. Pattersonb, Acta Pharmaceutica Sinica, 10, 19 (2020)

10. Linda S M Gulliver, Toxicology and Applied Pharmacology, 319, 69 (2017)

11. Lars-Oliver Klotz, Holger Steinbrenner, Redox Biology, 13, 646 (2017)

12. Jakub Maculewicza et al, Science of The Total Environment, 739, 140261 (2020)

13. Polyxeni Fountoucidoua et al, Toxicology Letter, 317, 24 (2019)

14. Mario Alberto Burgos-Aceves et al, Science of the Total Environment, 645, 79 (2018)

15. Francesco Visioli, PharmaNutrition, 3, 60 (2015)

16. V. V. Khudoley, Ecological genetics, 1, 30 (2003)

17. M. A. Zemlyanova et al. Human Ecology, 8, 8 (2012) 